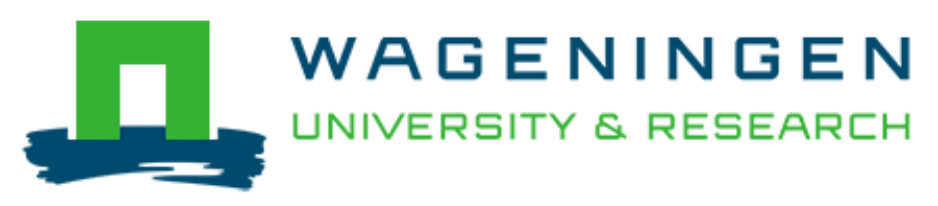

Benefits of herbivorous fish outweigh costs of corallivory in coral nurseries placed close to a Kenyan patch reef

Knoester, E. G., Murk, A. J., \& Osinga, R.

This is a "Post-Print" accepted manuscript, which has been published in "Marine Ecology Progress Series"

This version is distributed under a non-commercial no derivatives Creative Commons (c) (1) (9) (CC-BY-NC-ND) user license, which permits use, distribution, and reproduction in any medium, provided the original work is properly cited and not used for commercial purposes. Further, the restriction applies that if you remix, transform, or build upon the material, you may not distribute the modified material.

Please cite this publication as follows:

Knoester, E. G., Murk, A. J., \& Osinga, R. (2019). Benefits of herbivorous fish outweigh costs of corallivory in coral nurseries placed close to a Kenyan patch reef. Marine Ecology Progress Series, 611, 143-155. https://doi.org/10.3354/meps12869 
[copy-edited by T. Straza]

\title{
Benefits of herbivorous fish outweigh costs of corallivory in coral nurseries placed close to a Kenyan patch reef
}

\author{
E. G. Knoester*, A. J. Murk, R. Osinga \\ Marine Animal Ecology Group, Wageningen University, 6700 AH Wageningen, the \\ Netherlands \\ *Corresponding author: ewout.knoester@wur.nl \\ Running page head: Knoester et al.: Herbivory and corallivory at coral nurseries
}

\begin{abstract}
Coral mariculture involves time-consuming removal of fouling. On natural reefs, this service is provided by grazers. As natural reefs also harbour corallivores, it is debated whether reef-bound fish have a positive or negative effect on coral maricultured near natural reefs. This study quantified the net impact of herbivorous and corallivorous fish on coral mariculture. Nursery trees either uncaged, caged or as cage-control (15 per treatment) were placed near a patch reef at Wasini, Kenya, each hosting 10 Acropora verweyi fragments. From April to July 2016, survival and growth of the corals and bite marks on the corals were monitored. Using remote underwater video, bites by herbivorous and corallivorous fish were quantified. Upon termination of the experiment, dry weight of fouling from the nursery trees was determined. Caging of nurseries strongly reduced herbivory and corallivory. Results of cage-controls were not significantly different from uncaged trees. In caged nurseries, coral survival and growth were significantly lower than in uncaged nurseries, respectively $9 \%$ and $40 \%$ lower. Fouling was nearly $800 \%$ higher in caged nurseries. Herbivory was dominated by the surgeonfish Ctenochaetus striatus, which was responsible for $77 \%$ of the grazing. Monthly assessments showed bite marks on $10 \%$ of the uncaged coral fragments. Our study reveals that fouling control by herbivorous fish outweighs the costs of incidental corallivory on the survival and growth of $A$. verweyi. The vigour of unrestricted fouling, its negative impact on coral performance and the scarcity of corallivory justify the recommendation to place coral nurseries in Wasini near the reef.
\end{abstract}

KEY WORDS: Coral reef conservation $\cdot$ Coral gardening $\cdot$ Corallivory $\cdot$ Herbivory $\cdot$ Coralalgae interactions

\section{INTRODUCTION}

Triggered by the continuous degradation of tropical reefs, coral reef restoration initiatives have rapidly gained support around the turn of the last millennium (Rinkevich 2008). The aim of these active conservation initiatives is to improve the state of degraded reefs and mitigate local anthropogenic impacts to support higher resilience against large-scale disturbances, including climate change (Precht 2006, Hughes et al. 2007, Edwards et al. 2010). The practise of coral mariculture and reef restoration is still young and is partially conducted upon a scientific basis and partially upon trial and error. One of the limiting aspects of coral mariculture is the fight against fouling that hampers the performance of coral fragments by overgrowing them. This fouling is not happening on healthy reefs because of the grazing activity of herbivorous invertebrates and fish (Carpenter 1986, Hughes et al. 2007). It has been suggested, but not experimentally investigated, to place mid-water coral nursery structures near natural reef formations allowing roving herbivorous fish to visit the 
structures and consume fouling organisms (Edwards et al. 2010, Johnson et al. 2010). This would reduce the need for human-assisted cleaning efforts and thus project expenses (Shafir et al. 2006a, Frias-Torres et al. 2015). In contrast, other studies advise to isolate mid-water nursery structures from the natural reef in order to eliminate the negative impacts of corallivory (i.e. predation on coral) by fish and invertebrates. Coral nurseries have been isolated from the natural reef ranging from $1 \mathrm{~km}$ (Frias-Torres \& Van de Geer 2015), $3 \mathrm{~km}$ (Mbije et al. 2010, Horoszowski-fridman et al. 2011), $5 \mathrm{~km}$ (Levy et al. 2010), $8 \mathrm{~km}$ (Shafir et al. 2006b) to $13 \mathrm{~km}$ (Mbije et al. 2010). Coral nurseries have even been caged to prevent corallivory (Ferse \& Kunzmann 2009). Despite the fact that these reef restoration projects isolated and caged their nurseries to prevent corallivory, no study quantified the actual impact of corallivory on coral mariculture. In addition, no study considered the potentially negative impact of nursery isolation on coral performance through the absence of important reefassociated grazers of biofouling. Hence, quantitative studies on the effects of herbivory and corallivory on coral in mariculture are needed to complement the ample literature on these processes on natural reefs.

\subsection{Herbivory}

Dominant herbivores, such as fish and sea urchins, play a key role in tropical reef health, for their continuous grazing pushes the balance of competitive interactions between fouling organisms and corals towards scleractinian coral dominance (Carpenter 1986, Steneck 1988). From the diverse suite of fouling organisms, macroalgae seem the most widespread threat to scleractinian corals (Jompa \& McCook 2003). These macroscopic, fleshy and fast-growing algae can compete for space, food and light using several mechanisms, including overgrowth, shading, abrasion and allelopathy (Jompa \& McCook 2002). As a result, the coral colony receives less energy due to shading, polyp retraction and smothering (Tanner 1995) and becomes more prone to diseases and corallivory (Nugues et al. 2004, Wolf \& Nugues 2013). Experimental exclusion of roving herbivorous fish, the dominant grazers on healthy reefs, has resulted in unrestrained expansion of algal biomass in numerous studies (e.g. Thacker et al. 2001, Fox \& Bellwood 2007, Korzen et al. 2011), which, in turn, had negative impacts on coral growth, survival and fecundity (e.g. Tanner 1995, Hixon \& Brostoff 1996, Box \& Mumby 2007, Hughes et al. 2007). The question remains, however, whether roving herbivorous fish will effectively graze artificial nursery structures. Although grazing by herbivores has been shown an invaluable service to natural coral reefs, the benefit of fish-assisted cleaning to maricultured coral has not yet been quantified.

\subsection{Corallivory}

Dominant corallivores such as certain fish, gastropods and echinoderms inhibit coral growth through the consumption of live polyps and coral skeleton, while also leaving injuries. These injuries make the corals vulnerable to pathogens and fouling, reduce their energy production and increase their energy requirement for regeneration (Hall 1997). This impact was long considered insignificant, but more recent studies recognize corallivory as a potential important factor shaping coral reefs (Rotjan \& Lewis 2008). For example, corallivory by fish limits the local distribution of certain coral species (Neudecker 1979, Cole et al. 2008, Mumby 2009), and the main preyed coral species belong to same fast-growing genera (e.g. Acropora and Pocillopora) that are frequently used in reef restoration projects. In addition, coral in mariculture may be stressed and vulnerable through handling and fragmentation, potentially further increasing corallivory (Cole et al. 2008). Also, large herbivorous fish have been reported to accidently or on purpose scrape young coral fragments 
(e.g. Miller \& Hay 1998, Baria et al. 2010), while other fish have dislodged transplanted coral to reach invertebrate prey (Frias-Torres \& Van de Geer 2015). Corallivory could therefore impede the success of coral mariculture and a reef restoration project. However, until the impact of corallivorous fish on coral mariculture is systematically studied, there is no rational basis for decisions of placing coral nursery structures on isolated locations to limit corallivory.

\subsection{Research objective}

There are conflicting views on site selection for the placement of mid-water coral nursery structures. It remains unclear whether reef-bound fish have an overall positive or negative effect on coral mariculture as experimental studies are lacking. Both herbivory and corallivory have received scientific attention on the natural reef. However, the balance between these 2 important processes on coral in mariculture has remained unstudied and has been identified as a research priority in a recent review on coral reef restoration (Ladd et al. 2018). This study aims to address this knowledge gap by answering the following research question: What is the net impact of the local, reef-bound fish community at Wasini Island on the performance of corals in mariculture? The net impact was determined by experimental exclusion of fish from mid-water coral nursery structures (coral trees) located at a patch reef at Wasini Island, Kenya, hereby comparing the growth and survival of corals in uncaged and caged nurseries.

Based on the crucial role of herbivorous fish in maintaining scleractinian coral cover on reefs worldwide and the flourishing of natural reefs despite the presence of corallivorous fish at the study location, the benefit of grazing of fouling by herbivorous fish was expected to outweigh the cost of coral consumption by corallivorous fish in coral mariculture at this location. Thus, we hypothesise that coral survival and growth will be highest in uncaged nursery structures. The results of this study can be used to identify the best locations for placement of coral nurseries in the waters around Wasini Island.

\section{MATERIALS AND METHODS}

\subsection{Location}

The fish-exclusion study was conducted from April to July 2016 at a patch reef north of Wasini Island, Kenya (4 39' 34', S, 39 22' 56', E). Wasini Island and the study area (Fig. 1) are separated from the Kenyan mainland by a kilometre-wide channel. Coral patches are haphazardly scattered along the Wasini coastline between 2 to $5 \mathrm{~m}$ depth (low tide) and dominated by massive and branching corals from the genera Porites, Acropora, Pocillopora, Favia, Favites and Platygyra. Tidal difference reaches $4 \mathrm{~m}$ at spring tide and spans $2 \mathrm{~m}$ at neap tide. Visibility is typically $9 \pm 3 \mathrm{~m}$ (mean $\pm \mathrm{SD} ; \mathrm{n}=45)$, as measured by horizontal Secchi depth (range: $4-15 \mathrm{~m}$ ). Temperature dropped gradually during the study from $30^{\circ} \mathrm{C}$ in April to $26^{\circ} \mathrm{C}$ in July. Salinity remained stable at $36 \pm 1 \mathrm{ppt}($ mean $\pm \mathrm{SD} ; \mathrm{n}=45)$.

\subsection{Experimental design}

Three treatments were designed: a caged, uncaged and cage-control coral nursery. The nursery design resembled a small version of the commonly-used 'coral tree' nursery (Nedimyer et al. 2011). Like most coral nursery designs, it hinders access to invertebrates, thereby excluding the impact of herbivorous and corallivorous invertebrates from this study. The caged treatment (Fig. 2a) consisted of four $26 \mathrm{~cm}$ PVC pipes $(1.3 \mathrm{~cm} \varnothing)$ forming a cross using 2 T-joints. A $0.5 \times 0.5 \times 0.25 \mathrm{~m}^{3}$ cage made of galvanised monkey wire $\left(1.3 \times 1.3 \mathrm{~cm}^{2}\right.$ mesh size) was attached to the 4 PVC arms. Two opposite sides of the cage were hinged to 
enable coral growth measurements. A total of 10 clonal Acropora verweyi Veron \& Wallace, 1984 coral fragments were grown per nursery structure. A. verweyi was chosen for 3 reasons: Fragments were readily available around damaged colonies, the genus is frequently used in restoration projects worldwide (Edwards et al. 2010), and the species had experienced high predation pressure on its axial corallites in mid-water nurseries placed near $(5 \mathrm{~m})$ the natural reef of Wasini Island (E. Knoester pers. obs.). Naturally broken fragments of $A$. verweyi were collected at a patch reef at $4 \mathrm{~m}$ depth $\left(4^{\circ} 39^{\prime} 19.5^{\prime \prime} \mathrm{S}, 39^{\circ} 22^{\prime} 01.7^{\prime \prime} \mathrm{E}\right)$ and transported to the study location in seawater bins during a 5 min boat ride. At the study location, healthy parts of the coral were pruned into linear, thumb-sized fragments of $4.0 \pm 0.4 \mathrm{~cm}$ (mean $\pm \mathrm{SD} ; \mathrm{n}=$ 450 ) using heavy-duty wire cutters while on SCUBA and hung randomly into fishing-line loops with slipknots. A 1.51 PET bottle was used as subsurface buoy, and a $0.5 \mathrm{~m}$ nylon anchor line attached the PVC cross to a $10 \mathrm{~kg}$ concrete sinker. The caged treatment excluded access for all fish $>12 \mathrm{~cm}$, and smaller fish were assumed to exert negligible herbivory and corallivory (cf. Carpenter 1986, Ceccarelli et al. 2005, Fox \& Bellwood 2007). The uncaged treatment (Fig. $2 \mathrm{~b}$ ) provided unrestricted access to all fish. Differences in coral survival and growth between the caged and uncaged nursery structures were used to determine whether the fish community had a net positive or net negative impact on coral in mariculture. The cage-control treatment (Fig. 2c) was incorporated to check if any differences in coral survival and growth might be caused by the physical presence of the cage itself. This treatment was analogous to the caged design, but instead of hinged openings it had 2 sides of the cage completely removed to allow roving fish access to the coral fragments.

Fifteen replicates for each of the 3 treatments were deployed on 8 April 2016, totalling to 45 structures and 450 coral fragments. To reduce spatial confounding, a homogenous reef stretch of $100 \mathrm{~m}$ consisting of 10 coral patches was selected and treatments were assigned a position randomly. The coral patches are between 20 and $30 \mathrm{~m}$ in diameter, and between 3 and 6 treatments were placed around each coral patch. All treatments were placed near (i.e. within $1 \mathrm{~m}$ ) of a coral patch to encourage the interest of reef-bound fish (Frias-Torres \& Van de Geer 2015). Given the narrow depth range in which coral patches naturally occur in the study area, the structures were consequently placed within a narrow depth range of $3.1 \pm 0.7 \mathrm{~m}$ (mean $\pm \mathrm{SD} ; \mathrm{n}=45)$. Individual structures were separated by at least $2 \mathrm{~m}$. Cages and partial cages were cleaned at least weekly to limit cage artefacts such as shading and water flow reduction due to fouling. The experiment lasted for $100 \mathrm{~d}$.

\subsection{Measurements and analysis}

To test our hypothesis, coral performance (growth and survival) was measured and compared between the 3 treatments. To link patterns found in coral performance to the activity of grazers, fouling, herbivory and corallivory were also quantified on all 3 treatments. To characterize the local fish community and thus facilitate comparisons with other study areas, the fish community structure and fish abundance were determined.

\subsubsection{Coral performance}

Ecological volume (EV) of all coral fragments was determined roughly monthly. EV is defined as the total volume occupied by a coral, including the volume of water between its branches (Shafir et al. 2006a, Levy et al. 2010, Mbije et al. 2010). This volume (in $\mathrm{cm}^{3}$ ) was approximated by simplifying the form of the whole coral fragment to a cylinder: $E V=$ $\pi \times r^{2} \times l$. The increase in $\mathrm{EV}$ over the study period was assumed to reflect an exponential function: $E V_{t}=E V_{t-1} \times e^{S G R \times[t-(t-1)]}$, with $t$ in days and SGR being the specific growth rate in $\mathrm{d}^{-1}$ (Osinga et al. 2011). SGR was calculated using: 


$$
S G R={\ln \frac{E V_{t}}{E V_{t-1}} / t-(t-1)}^{.}
$$

Percentage colony survival was estimated approximately monthly for each fragment. Completely healthy fragments were used to start the experiment (100\% survival). Coral predation was quantified by identifying all new bite marks approximately monthly and estimating the EV of each removed part by comparing pictures taken during the current and previous measurement.

For each structure, the mean SGR, survival and bite marks were taken for the 10 coral fragments, and statistical analyses were carried out with the 45 nursery structures as independent observations. All statistical tests were performed using SPSS version 20. SGR, survival and bite marks were each analysed by a 2-way mixed ANOVA with treatment as between-subjects factor (caged, uncaged and cage-control) and time as within-subjects factor (Month 1, 2 and 3). Results were further analysed on main effects as none of the interactions between time and treatment were significant. ANOVAs were followed by a Tukey's post hoc test. One aberrant caged treatment was left out of the growth comparison because of strikingly low values (studentized residual values of -5.32 for SGR). This resulted in a sample size of 14 for all 3 treatments for growth, as an uncaged and cage-control structure were lost through local fishing activity. No other outliers were encountered based on studentized residual values. Approximate normality of data was evaluated by Q-Q plots, and transformations were made on survival (arcsine) and bite mark (square root) data to meet this assumption. Further assumptions were met, as confirmed by Levene's test of homogeneity of variance, Box's $M$ test for homogeneity of covariance and Mauchly's test of sphericity.

\subsubsection{Fouling}

At the end of the $100 \mathrm{~d}$ experiment, fouling was collected from the PVC pipes, monofilament loops and coral fragments. Collected fouling was categorized in the following functional groups: macroalgae, crustose coralline algae (CCA), epilithic algae matrix (EAM) and molluscs. Macroalgae are here defined as large $(>1 \mathrm{~cm})$ and fleshy algae. The EAM is defined as the assemblage of microalgae, filamentous algal turfs, juvenile stages of macroalgae and detrital material, all $<1 \mathrm{~cm}$ (sensu Marshell \& Mumby 2012). Fouling was sun-dried and weighed on an analytical balance (Sartorius BA 310P). Dry weight was standardized $\left(\mathrm{g} \mathrm{m}^{-2}\right)$ by dividing through the surface area of the nursery structures $\left(0.16 \mathrm{~m}^{2}\right)$.

A 1-way MANOVA with macroalgae, molluscs, CCA, EAM and total fouling as dependent variables was performed with treatments as a factor. Data were root-transformed to meet the assumption of normality. Transformed data conformed to the assumptions of univariate outliers (test: Mahalanobis distance), multivariate outliers (studentized residual values), multicollinearity (Pearson correlation) and linearity (scatter plots). The assumptions of homogeneity of covariance (Box's $M$ test) and variance (Levene's test) were not met, thus Pillai's Trace value and a Games-Howell post hoc test were used to interpret results. Post hoc test results for each fouling category were interpreted using a Bonferroni adjusted $\alpha$ level of 0.01 .

\subsubsection{Herbivory and corallivory}

Remote underwater video (RUV) observations were made to identify fish species and quantify their consumption of fouling and predation on coral. At $2 \mathrm{~m}$ distance from a nursery structure, divers placed a Canon 600D DSLR camera in a Neewer 40M case on a weighted $(10 \mathrm{~kg})$ König tripod (KN-TRIPOD40N). Using the free firmware add-on Magic Lantern, the camera was programmed to take nine 5 min recordings with 10 min intervals. Recordings initiated between 10:00 $\mathrm{h}$ and 14:00 $\mathrm{h}$, to coincide with the peak in foraging activity of most 
roving herbivorous fish (Hoey \& Bellwood 2009). All structures were first recorded at least once, thereafter additional RUVs were randomly made at the uncaged and cage-control treatments.

For analysis, RUV data was averaged per structure. For all 82 RUVs, the full $45 \mathrm{~min}$ of each recording was analysed ( $62 \mathrm{~h}$ of video) by identifying fish species, their size $(5 \mathrm{~cm}$ size classes) and summing their number of bites directed at fouling organisms (herbivory) and coral fragments (corallivory). As bite size is assumed to scale to fish body mass, number of bites were transformed to mass-scaled bites (bites g) to estimate the impact of feeding (Mantyka \& Bellwood 2007). The weight of each fish was estimated using the length-weight relationship $W=a \times L^{b}$, with weight $(W)$ in grams, $L$ as total length in $\mathrm{cm}$ (mid-point of respective size class) and $a$ and $b$ being estimations for each fish species by least-squares regression available in literature (Kulbicki et al. 2005). These mass-scaled bites were transformed to rates of herbivory and corallivory $\left(\right.$ bites $\mathrm{g} \mathrm{min}^{-1}$ ) by dividing the mass-scaled bites by the duration of the RUV (45 min). A 1-way MANOVA on herbivory and corallivory rates was performed to compare between treatments. Data were square-root transformed to meet the assumption of normality. Further assumptions were met, except for homogeneity of variance and covariance. Hence, the results were interpreted using Pillai's Trace value and Games-Howell post hoc tests.

\subsubsection{Fish abundance}

Fish abundance and composition were quantified by stationary underwater census (Bohnsack \& Bannerot 1986). This method identifies and lists all fish species that enter an imaginary cylinder ( $7.5 \mathrm{~m}$ radius) around a stationary diver for exactly $5 \mathrm{~min}$. After these initial $5 \mathrm{~min}$, the numbers of fish inside the cylinder are counted for all listed species. Time for these surveys averaged $10 \pm 2 \min ($ mean $\pm \mathrm{SD} ; \mathrm{n}=51$ ). Surveys were performed with randomly chosen nursery structures (independent of treatment) as mid-points for the surveys. All surveys commenced between 10:00 h and 14:00 h. The 51 performed surveys were averaged to 1 value for the overall study location, and fish numbers were transformed to density (fish ha ${ }^{-1}$ ) by extrapolating the mean number of fish from the survey area to hectare.

\section{RESULTS}

\subsection{Coral performance}

All data are presented as mean $\pm \mathrm{SE}$, unless stated otherwise. SGR of the coral fragments (Fig. 3A) differed significantly between treatments (2-way mixed ANOVA; $F_{2,39}=$ $18.20, \mathrm{p}<0.001)$ and over time $\left(F_{2,78}=34.07, \mathrm{p}<0.001\right)$, but no significant interaction was found (see Fig. A1 in the Appendix). SGR in the caged nursery structure $\left(0.0047 \pm 0.0010 \mathrm{~d}^{-}\right.$ $\left.{ }^{1}\right)$ was significantly lower than in both the uncaged $\left(0.0078 \pm 0.0010 \mathrm{~d}^{-1}\right)$ and cage-control $\left(0.0099 \pm 0.0010 \mathrm{~d}^{-1}\right)$ nursery structures (Tukey; $\mathrm{p}=0.003$ and $\mathrm{p}<0.001$, respectively). The latter 2 treatments did not differ significantly. Survival of coral fragments differed significantly between the treatments (2-way mixed ANOVA; $F_{2,40}=17.96, \mathrm{p}<0.001$ ). Average survival in caged nursery structures $(89 \pm 3 \%$ ) was significantly lower (Tukey; $\mathrm{p}<$ $0.001)$ than in both the uncaged $(98 \pm 2 \%)$ and cage-control $(99 \pm 1 \%)$ treatments; no significant difference was found between the latter 2 treatments (Fig. 3B). Over the course of the study, survival declined significantly each month $\left(F_{2,80}=57.74, \mathrm{p}<0.001\right)$, but no significant interaction was found between treatment and time.

\subsection{Fouling and herbivory}


Development of fouling showed profound treatment effects (Figs. $2 d-f \& 4$ ). The following categories of fouling did differ significantly between the treatments: molluscs (MANOVA; $\left.F_{2,36}=24.23, \mathrm{p}<0.001\right)$, macroalgae $\left(F_{2,36}=56.99, \mathrm{p}<0.001\right)$ and CCA $\left(F_{2,36}\right.$ $=6.03, \mathrm{p}<0.001)$. Also, the total sum of fouling differed significantly between treatments $\left(F_{2,36}=71.09, \mathrm{p}<0.001\right)$. At $484 \pm 43 \mathrm{~g} \mathrm{~m}^{-2}$, total fouling density was significantly higher (Games-Howell; $\mathrm{p}<0.001)$ in the caged treatment than in both the uncaged $\left(61 \pm 15 \mathrm{~g} \mathrm{~m}^{-2}\right)$ and cage-control $\left(78 \pm 17 \mathrm{~g} \mathrm{~m}^{-2}\right)$ treatments, the latter 2 treatments not being different from each other. Fouling by molluscs was dominated by mussels (Family: Mytilidae) and was significantly different between all 3 treatments $(p<0.01)$, with highest densities in the caged treatment $\left(224 \pm 34 \mathrm{~g} \mathrm{~m}^{-2}\right)$, followed by the cage-control $\left(25 \pm 11 \mathrm{~g} \mathrm{~m}^{-2}\right)$ and then by the uncaged structures $\left(10 \pm 7 \mathrm{~g} \mathrm{~m}^{-2}\right)$ (Fig. 4). Macroalgal density was $>100$-fold higher in the caged treatment $\left(130 \pm 21 \mathrm{~g} \mathrm{~m}^{-2} ; \mathrm{p}<0.001\right)$ than in the uncaged $\left(1 \pm 1 \mathrm{~g} \mathrm{~m}^{-2}\right)$ and cagecontrol $\left(1 \pm 2 \mathrm{~g} \mathrm{~m}^{-2}\right)$. Dominant macroalgae were Padina sp., Dictyota $\mathrm{sp}$. and unidentified red algae (division Rhodophyta). No significant difference in macroalgal density was found between the uncaged and cage-control treatment. CCA was significantly lower $(p<0.05)$ in the caged treatment $\left(2 \pm 2 \mathrm{~g} \mathrm{~m}^{-2}\right)$ compared to both the uncaged $\left(14 \pm 5 \mathrm{~g} \mathrm{~m}^{-2}\right)$ and cagecontrol $\left(10 \pm 5 \mathrm{~g} \mathrm{~m}^{-2}\right)$ treatments, which were not significantly different (Fig. 4). EAM (pooled mean $=35 \pm 9 \mathrm{~g} \mathrm{~m}^{-2}$ ) did not differ significantly between treatments.

Overall herbivory rates (Fig. 3C) were significantly different between treatments (MANOVA; $F_{2,40}=11.50, \mathrm{p}<0.001$ ), with rates being substantially lower in the caged treatment $\left(0 \pm 1\right.$ bites $\left.g \mathrm{~min}^{-1}\right)$ compared to the other 2 treatments (Games-Howell; $\left.\mathrm{p}<0.01\right)$. The uncaged $\left(83 \pm 35\right.$ bites $\left.\mathrm{g} \mathrm{min}^{-1}\right)$ and cage-control $\left(74 \pm 21\right.$ bites $\left.\mathrm{g} \mathrm{min}^{-1}\right)$ treatments did not differ significantly in grazing pressure. Rates of herbivory for the 8 most dominant grazers are presented in Fig. 5A. Grazing on the nursery structures was strongly dominated by a single species of surgeonfish, Ctenochaetus striatus, which took a sum of 205096 massscaled bites (77\% of total standardized bites). Bites of $C$. striatus could clearly be seen after the species visited the experimental structures, indicating removal and likely consumption of EAM by this species. Species composition of the most common herbivorous fish (Fig. 5B) corresponded partly with their contribution to grazing (Fig. 5A). The most common herbivorous fish was the small, territorial damselfish Plectroglyphidodon lacrymatus (298 fish $\mathrm{ha}^{-1}$ ), followed by the dominant grazer C. striatus (155 fish ha ${ }^{-1}$ ). The third most abundant was the surgeonfish Naso brevirostris $\left(140\right.$ fish ha $\left.{ }^{-1}\right)$, which was not recorded grazing.

\subsection{Corallivory}

A total of 1450 mass-scaled bites on coral fragments were recorded. There were no bite marks found on coral fragments inside cages. There was a significant difference neither in mean EV of bite marks between the uncaged $\left(0.017 \pm 0.006 \mathrm{~cm}^{3}\right)$ and cage-control $(0.023$ $\pm 0.007 \mathrm{~cm}^{3}$ ) treatments nor between the first, second and third month. Every month, bite marks were found on average on $10 \%$ of the coral fragments. Most of bites targeted axial corallites and growing tips of the fragments.

A significant difference in corallivory was found among the treatments (MANOVA; $\left.F_{2,40}=5.35, \mathrm{p}=0.009\right)$. The uncaged structures $\left(0.32 \pm 0.5\right.$ bites $\left.\mathrm{g} \mathrm{min}^{-1}\right)$ were subjected to significantly higher (Games-Howell; $p=0.021$ ) rates of corallivory than the caged treatment $\left(0 \pm 0.16\right.$ bites $\left.\mathrm{g} \mathrm{min}^{-1}\right)$, and the uncaged treatment did not differ from the cage-control $(0.09$ \pm 0.36 bites $\mathrm{g} \mathrm{min}^{-1}$ ). The 8 most dominant corallivorous fish (together responsible for $90 \%$ of the 1450 mass-scaled bites) were Chlorurus sordidus (24\%), C. striatus (23\%), $P$. lacrymatus (14\%), Chaetodon melannotus (9\%), Chaetodon trifasciatus (7\%), Gomphosus caeruleus (5\%), Thalassoma lunare (4\%) and Chaetodon kleinii (4\%). 
The aim of this study was to determine the net impact of the local, reef-bound fish community at Wasini Island on coral in mariculture. We hypothesised that coral survival and growth would be higher in uncaged nursery structures because the benefits of the fish community through fouling control by herbivorous fish were expected to outweigh the negative impacts of corallivorous fish. Here, first the methodology of the study is discussed. Following this evaluation of the experimental set-up, the role of herbivorous and corallivorous fish at Wasini Island on coral in mariculture will be discussed. The discussion concludes with a recommendation on the placement of nurseries at Wasini Island, general management recommendations and future perspectives for coral mariculture projects in other areas of the world.

\subsection{Methodological considerations}

The coral tree nursery design chosen in this study excluded access of grazing invertebrates. Though inclusion of invertebrates would make the study more complete, it is believed that such nursery designs are less advantageous because both algal proliferation and corallivory have been reported to be much higher in such designs (Edwards et al. 2010). As our goal is to further increase the efficiency of nurseries, the focus on the preferable, invertebrate-excluding coral trees is justified. The uncaged and cage-control treatments generated equivalent results on nearly all aspects, strongly indicating that secondary cage artefacts have not confounded the results of this study, which, according to Steele (1996), is a potential pitfall for cage exclusion studies. The large mesh size and weekly cleaning apparently minimised alterations in light and current, resulting in equal coral growth, coral survival and the development of a similar fouling community between the uncaged and cagecontrol nursery structures, except for fouling by molluscs. The intermediate effect found for molluscs was likely caused by the partial cage partially precluding the bulky, molluscdevouring triggerfish Balistoides viridescens (Frias-Torres \& Van de Geer 2015). Deterrence of corallivorous fish by partial cages, as found in some studies (e.g. Miller \& Hay 1998, Baria et al. 2010), was not detected here, and bite marks were equally distributed between uncaged and cage-control treatments. The spatially complex reef has likely prevented the use of partial cages as additional refuge (Carpenter 1986), and rates of herbivory were therefore equal between uncaged and cage-control structures. However, it was observed during cleaning dives that the large mesh size did allow access of small $(<12 \mathrm{~cm}$ total length) and slender fish such as juvenile Scarus ghobban and Thalassoma lunare inside caged treatments, but this resulted only in insignificant amounts of herbivory given the seemingly unconstrained growth of macroalgae inside these caged treatments. Thus, the design of the cages has proven successful in practically excluding herbivory and corallivory, without generating secondary cage artefacts.

The combination of RUV and stationary underwater census approaches demonstrated which fish were the dominant daytime grazers of the nursery structures and that any differences found in the caged treatment are principally due to the exclusion of fish. Though herbivory is captured well, $62 \mathrm{~h}$ of RUV revealed not a single fish consuming coral skeleton. Nonetheless, bite marks on the coral fragments were found each month. The identity of the fish species responsible for these bite marks thus remains unknown. For some species, such as the obligate corallivores Chaetodon melannotus and Chaetodon trifasciatus, the bites recorded on RUV likely reflect actual cases of tissue corallivory, leaving the coral skeleton intact: these fish predate on individual coral polyps (Cole et al. 2008). For other herbivores and omnivores such as Chlorurus sordidus, Ctenochaetus striatus and Plectroglyphidodon lacrymatus, it is more likely that they targeted minute algae and other fouling growing on the 
coral. In conclusion, the recorded bite marks accurately quantify predation on coral skeleton, though the perpetrator remains unknown, and tissue predation is likely performed only by a subset of the 'corallivorous' species recorded on RUV.

\subsection{Positive effects of herbivores}

C. striatus, responsible for $77 \%$ of all mass-scaled bites, and other grazing fish forestalled the development of an abundant fouling community on the uncaged and cagecontrol nursery structures. Some authors have proposed that profuse increases in algal biomass, and an eventual shift from coral to algal dominance on reefs, could be a peculiarity of overfished Caribbean reefs only (Roff \& Mumby 2012). At the end of this $100 \mathrm{~d}$ study on the East African coast, however, macroalgal density was 100 -fold higher in caged structures compared to uncaged structures and showed no sign of recession. After an initial bloom of EAM, Phaeophyta and Rhodophyta quickly took over and formed a climax community. Such profound increases in macroalgal biomass appear to be the common development in the absence of fish, also outside the Caribbean (Rasher et al. 2012), and attest the importance of fish in controlling the standing stock of algae by their continuous grazing, consuming up to $90 \%$ of the daily algal production (Carpenter 1986). In contrast, the continuous grazing by fish on the uncaged and cage-control nursery structures supported the formation of a CCA crust. These early-successional CCA keep the substrate free from macroscopic fouling and also enhance natural settlement of coral larvae (Belliveau \& Paul 2002). Thus, while the importance of herbivorous fish in structuring the benthic community and favouring CCA and scleractinian coral dominance at natural reefs has long been established, now their potential role in controlling algal biomass on coral nursery structures has been clearly demonstrated as well.

SGR of coral fragments in the uncaged $\left(0.0078 \mathrm{~d}^{-1}\right)$ and cage-control $\left(0.0099 \mathrm{~d}^{-1}\right)$ structures were comparable to growth rates of branching coral found in previous (restoration) studies (e.g. Shafir et al. 2006a, Levy et al. 2010, Osinga et al. 2011). Survival after $100 \mathrm{~d}$ was notably high for the uncaged (98\%) and cage-control fragments (99\%). Considering the seemingly intense competition between coral and fouling in caged structures, with most fragments fully overgrown and barely visible (Fig. 2d), coral survival (89\%) and growth $\left(0.0047 \mathrm{~d}^{-1}\right)$ were still respectable in the caged treatment. Surprisingly, the decreases in coral survival and growth in the caged treatment did not accelerate over time compared to the other treatments, despite an ever-increasing quantity of fouling. Nevertheless, $9 \%$ higher survival and a $40 \%$ increase in SGR in the uncaged treatment indicate very meaningful advantages of growing coral near natural fish communities. In particular, the presence of macroalgae is likely to have a direct negative impact on coral. An earlier exclusion study on herbivory and corallivory on a natural reef found no net impact of the fish community on coral recruit survival, but did show a shift from predation-induced mortality of uncaged recruits towards mortality caused by competing turf algae for caged recruits (Penin et al. 2011). The observed decreases in survival and growth of caged coral in this study are most likely also directly attributable to competitive mechanisms of fouling organisms, such as overgrowth, shading and abrasion, in particular by macroalgae (Jompa \& McCook 2002, Box \& Mumby 2007). Though mollusc weight was also elevated in caged structures, their presence is unlikely to have been detrimental to the coral as their shells represent much of the weight, and the molluscs themselves occupied relatively small surface areas. In addition, molluse density was more than twice as high in the cage-control compared to uncaged structures, but growth and survival did not differ between these 2 treatments. Our results support previous studies on natural reefs and show that favourable conditions for coral survival and growth, including on 
artificial structures, are largely due to grazing fish preventing macroalgae from outcompeting coral.

\subsection{Negative effects of corallivores}

Advantages for coral in the uncaged and cage-control treatments created by grazing herbivorous fish could have been reduced by direct predation on coral by corallivorous fish. One study reported that the negative effect of corallivores completely offset the positive effect of herbivores (Miller \& Hay 1998). In this present study, however, only $10 \%$ of coral fragments showed bites marks each month, representing only very small absolute volumes of consumed coral. Nonetheless, the majority of bites were targeted at axial corallites, and the removal of these growing tips is likely to retard coral growth (Lirman et al. 2010). Furthermore, predation increases the susceptibility of coral to diseases (Sheridan et al. 2013). Though on an individual basis corallivory can have a grave impact on the survival and growth of a coral fragment, the rarity of such events has rendered its overall negative effect rather small, especially compared to the positive effects of herbivory by fish. Also, the arborescent growth form of the Acropora genus is known for its high regenerative capabilities (Hall 1997), and this might have mitigated partly the negative impact of corallivory. The potentially increased corallivory on stressed fragments (Cole et al. 2008) was not seen in this study. Corallivory remained constant over the experimental period and was not higher in the initial month when corals may have been stressed due to handling or fragmentation. This study on Acropora verweyi maricultured near natural reefs shows some negative impact of corallivory on growth of coral fragments, but this is not offsetting the beneficial effects of herbivory, as reflected by the better growth and survival in the uncaged and cage-control nurseries. These results correspond well with studies that examined the merits of herbivory versus corallivory on the natural reef (Mumby 2009). Interestingly, none of the fish captured on RUV targeting the coral fragments are known to be consumers of coral skeleton and are more likely to have been targeting coral tissue only. Future studies with longer RUV recordings or detailed in-field observations might reveal the identity of the skeleton-consuming fish.

\subsection{Limited functional redundancy}

The control of fouling through continuous grazing was dominated by a single species, although 18 roving herbivorous fish were censused. C. striatus kept the nursery structures clean by regularly grazing early successional stages of fouling (see also Marshell \& Mumby 2012 ) and was solely accountable for $77 \%$ of all mass-scaled bites taken during the experiment. Such apparent limited functional redundancy at highly diverse reefs seems common, and single-species dominance in herbivory has been encountered in various other studies, for example by Siganus rivulatus (Fox \& Bellwood 2007), Platax pinnatus (Bellwood et al. 2006) and Naso unicornis (Bellwood et al. 2003). Though fish from the Acanthuridae family are recognized as important herbivores and detrivores, no preceding study could be found in which $C$. striatus is the dominant grazer. This is surprising, given the wide distribution and generally high abundance of $C$. striatus in the Indo-Pacific (Marshell \& Mumby 2012). C. striatus used to be considered a detrivore only consuming detritus without impacting algae, but new research by Marshell \& Mumby (2012) has shown that C. striatus actually removes algae as well, a conclusion supported by this study. Other species frequently recorded on RUV are considered herbivores, such as Centropyge sp., Zebrasoma sp.

(Clements et al. 2017) and Plectroglyphidodon sp. (Jones et al. 2006), whereas Scarus sp. and Chlorurus sp. might only target microorganisms living in or on the EAM and macroalgae (Clements et al. 2017). Shifts in dominance among the common species between different 
areas remain inexplicable, though this variability is likely dependent on their relative abundance, the food availability, food palatability and seasonal variation (Hoey \& Bellwood 2009 ) and perhaps also on selective removal of certain herbivorous species by fishing. In the aforementioned studies, the dominant macroalgal grazers were, surprisingly, often not the numerically dominant herbivores. In this current study, however, the dominant grazer $C$. striatus was also the most abundant roving herbivore. For the studied location, this facilitates the selection of nursery sites, which can simply be based on the local species composition and abundance as determined by fish surveys. In short, despite the presence of a diverse assemblage of herbivorous fish, grazing was dominated by $C$. striatus, locally the most common roving herbivorous fish.

\section{CONCLUSION}

The vigour of unrestricted fouling organisms, their negative impact on coral growth and survival through competition and the scarcity of corallivory justify the recommendation to place coral nursery structures near natural fish assemblages in the Wasini Channel. As hypothesised, the advantage of having biological fouling control by herbivorous fish outweighs the negative impacts of incidental corallivory on the survival and growth of $A$. verweyi. Coral that was easily accessible to the natural fish assemblage attained very high levels of survival and good coral growth without the need of human-assisted cleaning for a period of $100 \mathrm{~d}$. Nonetheless, the balance between herbivory and corallivory will depend on the site-specific fish assemblage and can be difficult to predict due to a potential discrepancy between fish abundance and functional impact. Also, roving herbivorous and coralivorous fish might visit isolated nursery structures (Shafir et al. 2006b); thus, it is possible that structures away from the natural reef receive some bio-assistance or suffer from predation as well. A deeper understanding between the abundance of herbivorous and corallivorous fish and their functional role will greatly enhance our capabilities to identify and use beneficial fish assemblages for mariculturing coral. The approach presented in this study, through monitoring and comparing small fish-exclusion nurseries to uncaged and cage-control nurseries regarding coral survival and growth, development of fouling, occurrence of bite marks and herbivory and corallivory, is recommended to be used at other reef restoration projects to evaluate the net impact of their local fish communities on coral mariculture. In addition, it is recommended that future research directly compares isolated nurseries with nurseries placed near natural reefs, to quantify the effects of isolation. Given the apparent limited functional redundancy of herbivorous fish found in this and previous studies, it is recommended to consider and protect functionally important key species in fisheries management. This study at the patch reefs of Wasini Island indicated that its fish assemblage favours coral survival and growth. Such free animal-assisted cleaning not only promotes coral survival and growth but also reduces human cleaning time and thus project costs, ultimately benefitting the restoration of reefs.

Acknowledgements. We are much indebted to Harm and Selina Lutjeboer for their logistics support. We fully support Eric Stokman for initiating the REEFolution Foundation. We appreciate Hamadi Mwamlavya's effort to design the study map and thank Rianne Laan and Yatin Patel for their field work assistance and many memorable dives. We thank 3 anonymous reviewers for their input which helped to sharpen the focus of our manuscript.

\section{LITERATURE CITED}

\footnotetext{
$<$ jrn>Baria MVB, Guest JR, Edwards AJ, Aliño PM, Heyward AJ, Gomez ED (2010) Caging enhances post-settlement survival of juveniles of the scleractinian coral Acropora tenuis. J Exp Mar Biol Ecol 394:149-153 doi:10.1016/j.jembe.2010.08.003</jrn>
} 
$<$ jrn>Belliveau SA, Paul VJ (2002) Effects of herbivory and nutrients on the early colonization of crustose coralline and fleshy algae. Mar Ecol Prog Ser 232:105-114 doi: $10.3354 /$ meps $232105</$ jrn $>$

$<$ jrn>Bellwood DR, Hoey AS, Choat JH (2003) Limited functional redundancy in high diversity systems: resilience and ecosystem function on coral reefs. Ecol Lett 6:281-285 doi:10.1046/j.1461-0248.2003.00432. $<$ <jrn $>$

$<$ jrn>Bellwood DR, Hughes TP, Hoey AS (2006) Sleeping functional group drives coral-reef recovery. Curr Biol 16:2434-2439 PubMed doi:10.1016/j.cub.2006.10.030</jrn>

$<$ jrn>Bohnsack JA, Bannerot SP (1986) A stationary visual census technique for quantitatively assessing community structure of coral reef fishes. NOAA Tech Rep NMFS $41</$ jrn $>$

$<$ jrn>Box SJ, Mumby PJ (2007) Effect of macroalgal competition on growth and survival of juvenile Caribbean corals. Mar Ecol Prog Ser 342:139-149 doi:10.3354/meps342139</jrn>

$<$ unknown >Carpenter RC (1986) Partitioning herbivory and its effects on coral reef algal communities. Ecol Monogr 56:345-364 doi:10.2307/1942551</unknown>

$<$ jrn>Ceccarelli DM, Jones GP, McCook LJ (2005) Foragers versus farmers: contrasting effects of two behavioural groups of herbivores on coral reefs. Oecologia 145:445-453 PubMed doi:10.1007/s00442-005-0144-y $<$ jrn $>$

$<$ jrn $>$ Clements KD, German DP, Piché J, Tribollet AD, Choat JH (2017) Integrating ecological roles and trophic resources on coral reefs: multiple lines of evidence identify parrotfishes as microphages. Biol J Linn Soc 120:729-751</jrn>

$<$ jrn $>$ Cole AJ, Pratchett MS, Jones GP (2008) Diversity and functional importance of coralfeeding fishes on tropical coral reefs. Fish Fish 9:286-307 doi:10.1111/j.14672979.2008.00290. $\mathrm{x}</ \mathrm{jrn}>$

$<$ bok $>$ Edwards AJ, Guest JR, Shafir S, Fisk D and others (2010) Reef rehabilitation manual. St Lucia, Australia $<$ /bok $>$

$<$ jrn>Ferse SCA, Kunzmann A (2009) Effects of concrete-bamboo cages on coral fragments: evaluation of a low-tech method used in artisanal ocean-based coral farming. J Appl Aquacult 21:31-49 doi:10.1080/10454430802694538</jrn>

$<$ jrn>Fox RJ, Bellwood DR (2007) Quantifying herbivory across a coral reef depth gradient. Mar Ecol Prog Ser 339:49-59 doi:10.3354/meps339049</jrn>

$<$ jrn>Frias-Torres S, Van de Geer C (2015) Testing animal-assisted cleaning prior to transplantation in coral reef restoration. PeerJ 3:e1287 PubMed doi:10.7717/peerj. $1287</$ jrn $>$

$<$ jrn $>$ Frias-Torres S, Goehlich H, Reveret C, Montoya-Maya PH (2015) Reef fishes recruited at midwater coral nurseries consume biofouling and reduce cleaning time in Seychelles, Indian Ocean. Afr J Mar Sci 2338:1-6</jrn>

$<j r n>$ Hall VR (1997) Interspecific differences in the regeneration of artificial injuries on scleractinian corals. J Exp Mar Biol Ecol 212:9-23 doi:10.1016/S0022-0981(96)02760$\underline{8}</ \mathrm{jrn}>$

$<$ jrn>Hixon MA, Brostoff WN (1996) Succession and herbivory: effects of differential fish grazing on Hawaiian coral-reefs algae. Ecol Monogr 66:67-90 doi: $10.2307 / 2963481</$ jrn $>$ 
$<$ jrn>Hoey AS, Bellwood DR (2009) Limited functional redundancy in a high diversity system: single species dominates key ecological process on coral reefs. Ecosystems 12:1316-1328 doi:10.1007/s10021-009-9291-z</jrn>

$<$ jrn>Horoszowski-fridman YB, Izhaki I, Rinkevich B (2011) Engineering of coral reef larval supply through transplantation of nursery-farmed gravid colonies. J Exp Mar Biol Ecol 399:162-166 doi:10.1016/j.jembe.2011.01.005 </jrn>

$<$ jrn>Hughes TP, Rodrigues MJ, Bellwood DR, Ceccarelli DM and others (2007) Phase shifts, herbivory, and the resilience of coral reefs to climate change. Curr Biol 17:360365 PubMed doi:10.1016/j.cub.2006.12.049</jrn>

<unknown>Johnson ME, Key S, Bartels E, Beach D, Larson L (2010) Best practices for propagation and population enhancement: Caribbean Acropora restoration guide, The Nature Conservancy, Arlington, $\mathrm{VA}</$ unknown $>$

$<$ jrn>Jompa J, McCook LJ (2002) The effects of nutrients and herbivory on competition between a hard coral (Porites cylindrica) and a brown alga (Lobophora variegata). Limnol Oceanogr 47:527-534 doi:10.4319/1o.2002.47.2.0527</jrn>

$<$ jrn>Jompa J, McCook LJ (2003) Coral-algal competition: macroalgae with different properties have different effects on corals. Mar Ecol Prog Ser 258:87-95 doi: $10.3354 /$ meps $258087</$ jrn $>$

$<$ jrn> Jones GP, Santana L, McCook LJ, McCormick MI (2006) Resource use and impact of three herbivorous damselfishes on coral reef communities. Mar Ecol Prog Ser 328:215224 doi: $10.3354 / \mathrm{meps} 328215</$ jrn $>$

$<$ jrn>Korzen L, Israel A, Abelson A (2011) Grazing effects of fish versus sea urchins on turf algae and coral recruits: possible implications for coral reef resilience and restoration. $\mathrm{J}$ Mar Biol 2011:1-8 doi:10.1155/2011/960207</jrn>

$<$ jrn>Kulbicki M, Guillemot N, Amand M (2005) A general approach to length-weight relationships for New Caledonian lagoon fishes. Cybium 29:235-252</jrn $>$

$<$ jrn>Ladd MC, Miller MW, Hunt JH, Sharp WC, Burkepile DE (2018) Harnessing ecological processes to facilitate coral restoration. Front Ecol Environ 16:239-247 doi: $10.1002 /$ fee. $1792</$ jrn $>$

$<$ jrn>Levy G, Shaish L, Haim A, Rinkevich B (2010) Mid-water rope nursery: testing design and performance of a novel reef restoration instrument. Ecol Eng 36:560-569 doi:10.1016/j.ecoleng.2009.12.003 $<$ jrn $>$

$<$ jrn $>$ Lirman D, Thyberg T, Herlan J, Hill C and others (2010) Propagation of the threatened staghorn coral Acropora cervicornis: methods to minimize the impacts of fragment collection and maximize production. Coral Reefs 29:729-735 doi:10.1007/s00338-010$\underline{0621-6}<$ jrn $>$

$<$ jrn>Mantyka CS, Bellwood DR (2007) Direct evaluation of macroalgal removal by herbivorous coral reef fishes. Coral Reefs 26:435-442 doi:10.1007/s00338-007-0214$\underline{1}</ \mathrm{jrn}>$

$<\mathrm{jrn}>$ Marshell A, Mumby PJ (2012) Revisiting the functional roles of the surgeonfish Acanthurus nigrofuscus and Ctenochaetus striatus. Coral Reefs 31:1093-1101 doi:10.1007/s00338-012-0931-y</jrn>

$<$ jrn>Mbije NE, Spanier E, Rinkevich B (2010) Testing the first phase of the 'gardening concept' as an applicable tool in restoring denuded reefs in Tanzania. Ecol Eng 36:713- 
$<$ jrn $>$ Miller MW, Hay ME (1998) Effects of fish predation and seaweed competition on the survival and growth of corals. Oecologia 113:231-238 PubMed doi:10.1007/s004420050373</jrn>

$<$ jrn>Mumby PJ (2009) Herbivory versus corallivory: Are parrotfish good or bad for Caribbean coral reefs? Coral Reefs 28:683-690 doi:10.1007/s00338-009-0501-0</jrn>

$<$ jrn>Nedimyer K, Gaines K, Roach S (2011) Coral tree nursery: an innovative approach to growing corals in an ocean-based field nursery. Aquacult Aquarium Conserv Legis $4: 442-446</ \mathrm{jrn}>$

$<\mathrm{jrn}>$ Neudecker S (1979) Effect of grazing and browsing fishes on the zonation of corals in Guam. Ecology 60:666-672 doi:10.2307/1936602</jrn>

$<$ jrn>Nugues MM, Smith GW, Van Hooidonk RJ, Seabra MI, Bak RPM (2004) Algal contact as a trigger for coral disease. Ecol Lett 7:919-923 doi:10.1111/j.1461$\underline{0248.2004 .00651 . \mathrm{x}}</ \mathrm{jrn}>$

$<$ jrn $>$ Osinga R, Schutter M, Griffioen B, Wijffels RH and others (2011) The biology and economics of coral growth. Mar Biotechnol (NY) 13:658-671 PubMed doi:10.1007/s10126-011-9382-7</jrn>

$<$ jrn $>$ Penin L, Michonneau F, Carroll A, Adjeroud M (2011) Effects of predators and grazers exclusion on early post-settlement coral mortality. Hydrobiologia 663:259-264 doi:10.1007/s10750-010-0569-0</jrn>

$<$ unknown $>$ Precht WF (2006) Coral reef restoration handbook. CRC Press, Boca Raton, $\mathrm{FL}</$ unknown $>$

$<$ jrn>Rasher DB, Engel S, Bonito V, Fraser GJ, Montoya JP, Hay ME (2012) Effects of herbivory, nutrients, and reef protection on algal proliferation and coral growth on a tropical reef. Oecologia 169:187-198 PubMed doi:10.1007/s00442-011-2174-y $</$ jrn $>$

$<$ jrn>Rinkevich B (2008) Management of coral reefs: We have gone wrong when neglecting active reef restoration. Mar Pollut Bull 56:1821-1824 PubMed doi:10.1016/j.marpolbul.2008.08.014 </jrn>

$<$ jrn>Roff G, Mumby PJ (2012) Global disparity in the resilience of coral reefs. Trends Ecol Evol 27:404-413 PubMed doi:10.1016/j.tree.2012.04.007</jrn>

$<$ jrn>Rotjan RD, Lewis SM (2008) Impact of coral predators on tropical reefs. Mar Ecol Prog Ser 367:73-91 doi:10.3354/meps07531</jrn>

$<$ jrn $>$ Shafir S, Van Rijn J, Rinkevich B (2006a) Steps in the construction of underwater coral nursery, an essential component in reef restoration acts. Mar Biol 149:679-687 doi:10.1007/s00227-005-0236-6</jrn>

$<$ conf $>$ Shafir S, Van Rijn J, Rinkevich B (2006b) A mid water coral nursery. Proc 10th Int Coral Reef Symp, Okinawa 1:1674$1679</$ conf $>$ http://www.reefbase.org/download/download.aspx?type=1\&docid=12484

$<$ jrn $>$ Sheridan C, Kramarsky-Winter E, Sweet MJ, Kushmaro A, Leal MC (2013) Diseases in coral aquaculture: causes, implications and preventions. Aquaculture 396-399:124-135 doi:10.1016/j.aquaculture.2013.02.037 </jrn>

$<$ jrn>Steele MA (1996) Effects of predators on reef fishes: separating cage artifacts from effects of predation. J Exp Mar Biol Ecol 198:249-267 doi:10.1016/0022- 
$<$ conf $>$ Steneck RS (1988) Herbivory on coral reefs: a synthesis. Proc 6th Int Coral Reef Symp, Townsville 1:37-

49</conf $>$ http://www.reefbase.org/download/download.aspx?type=1\&docid=10376

$<$ jrn>Tanner JE (1995) Competition between scleractinian corals and macroalgae: an experimental investigation of coral growth, survival and reproduction. J Exp Mar Biol Ecol 190:151-168 doi:10.1016/0022-0981(95)00027-O </jrn>

$<$ jrn $>$ Thacker R, Ginsburg D, Paul VJ (2001) Effects of herbivore exclusion and nutrient enrichment on coral reef macroalgae and cyanobacteria. Coral Reefs 19:318-329 doi: $10.1007 / \mathrm{s} 003380000122</ \mathrm{jrn}>$

$<$ jrn> Wolf AT, Nugues MM (2013) Synergistic effects of algal overgrowth and corallivory on Caribbean reef-building corals. Ecology 94:1667-1674 PubMed doi:10.1890/12$\underline{0680.1}</$ jrn $>$ 


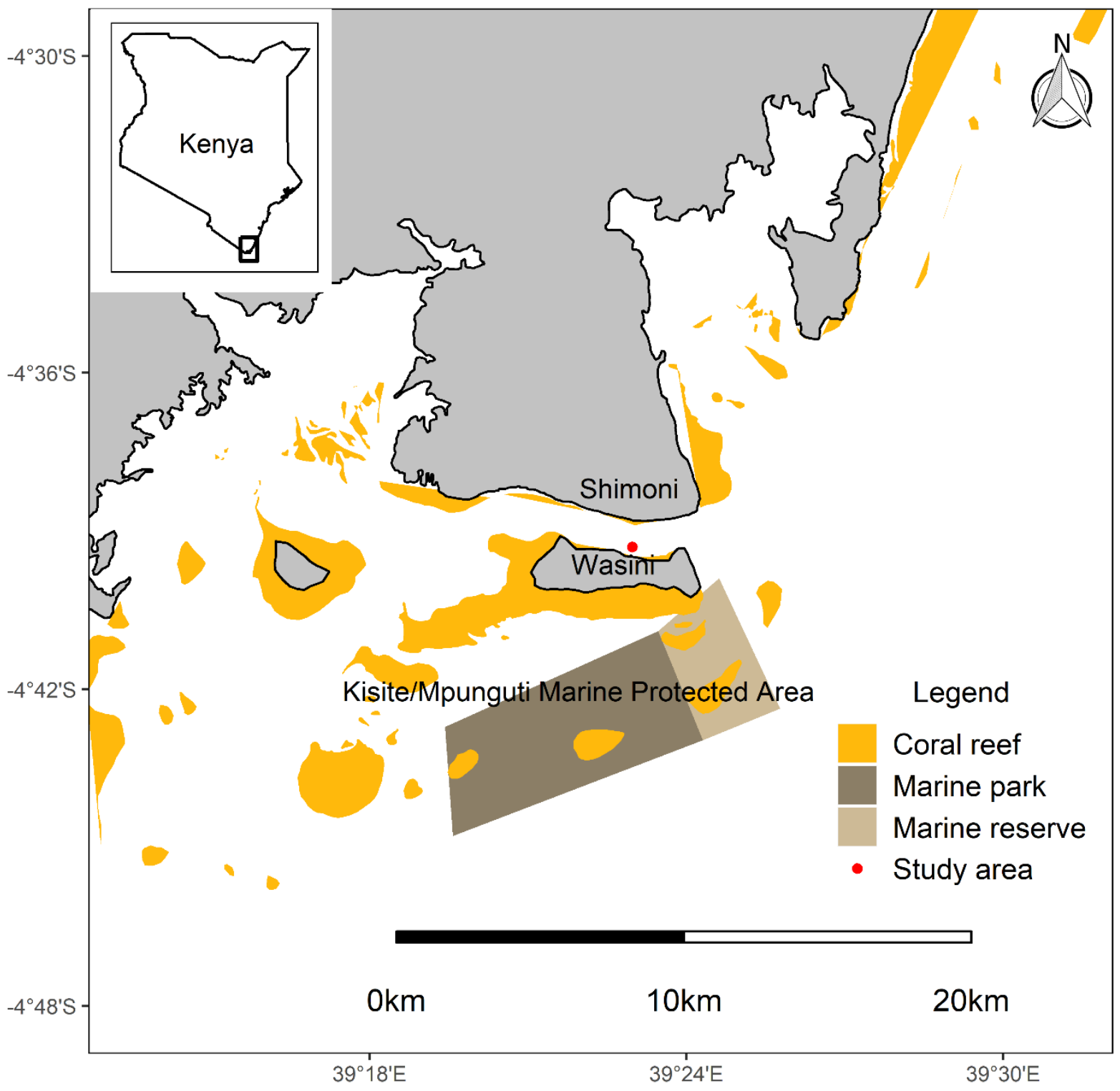

655 Fig. 1 Map of the study area (•) in the Wasini Channel, located between 656 Shimoni village on the Kenyan mainland and Wasini Island. The study area $\left.657 \mathbf{( 4}^{\circ} 39^{\prime} 34^{\prime \prime S}, 3^{\circ} 22^{\prime} 56 " \mathrm{E}\right)$ consisted of a 100 -meter stretch of patch reef 

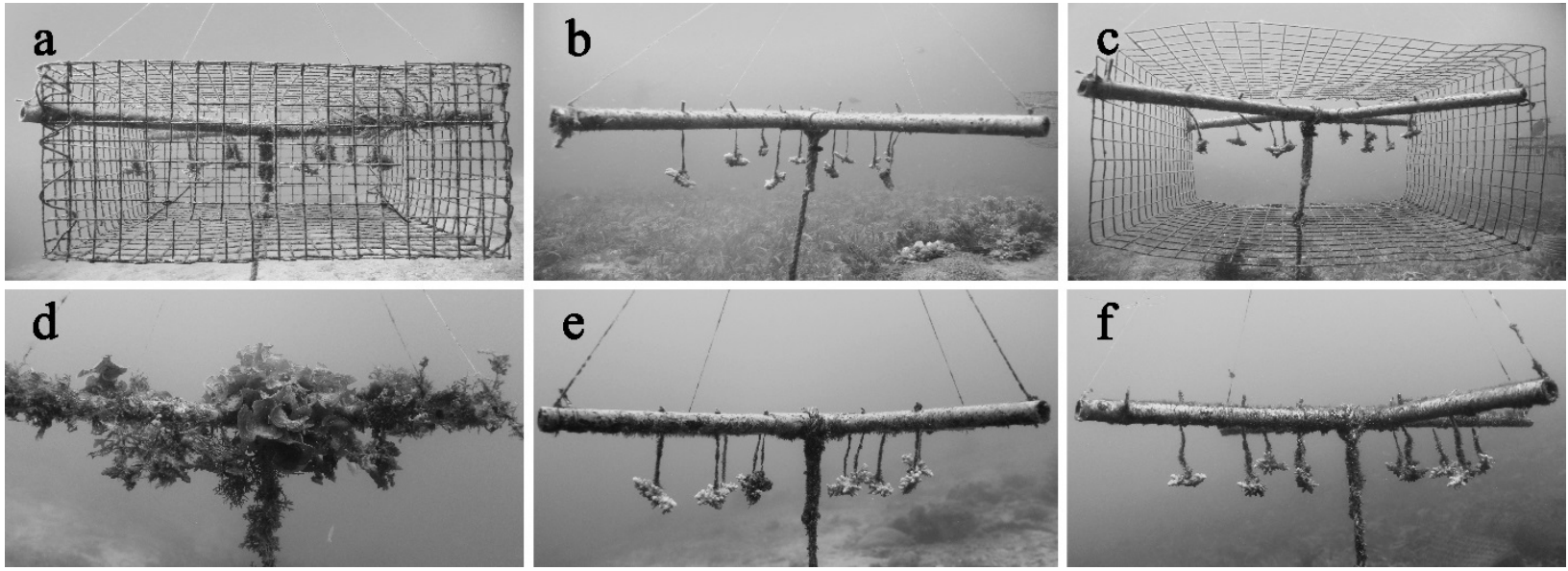

Fig. 2 The three treatment designs deployed in the Wasini Channel (Kenya) at the start and end of the experiment. Top row shows coral nursery structures one week after deployment (a caged treatment, b uncaged treatment, c cagecontrol treatment) and bottom rows depicts them at the end of the 100-day study to show the development of fouling assemblages (d caged treatment, e uncaged treatment, f cage-control treatment). The cage and partial cage were removed just before taking the end photographs 

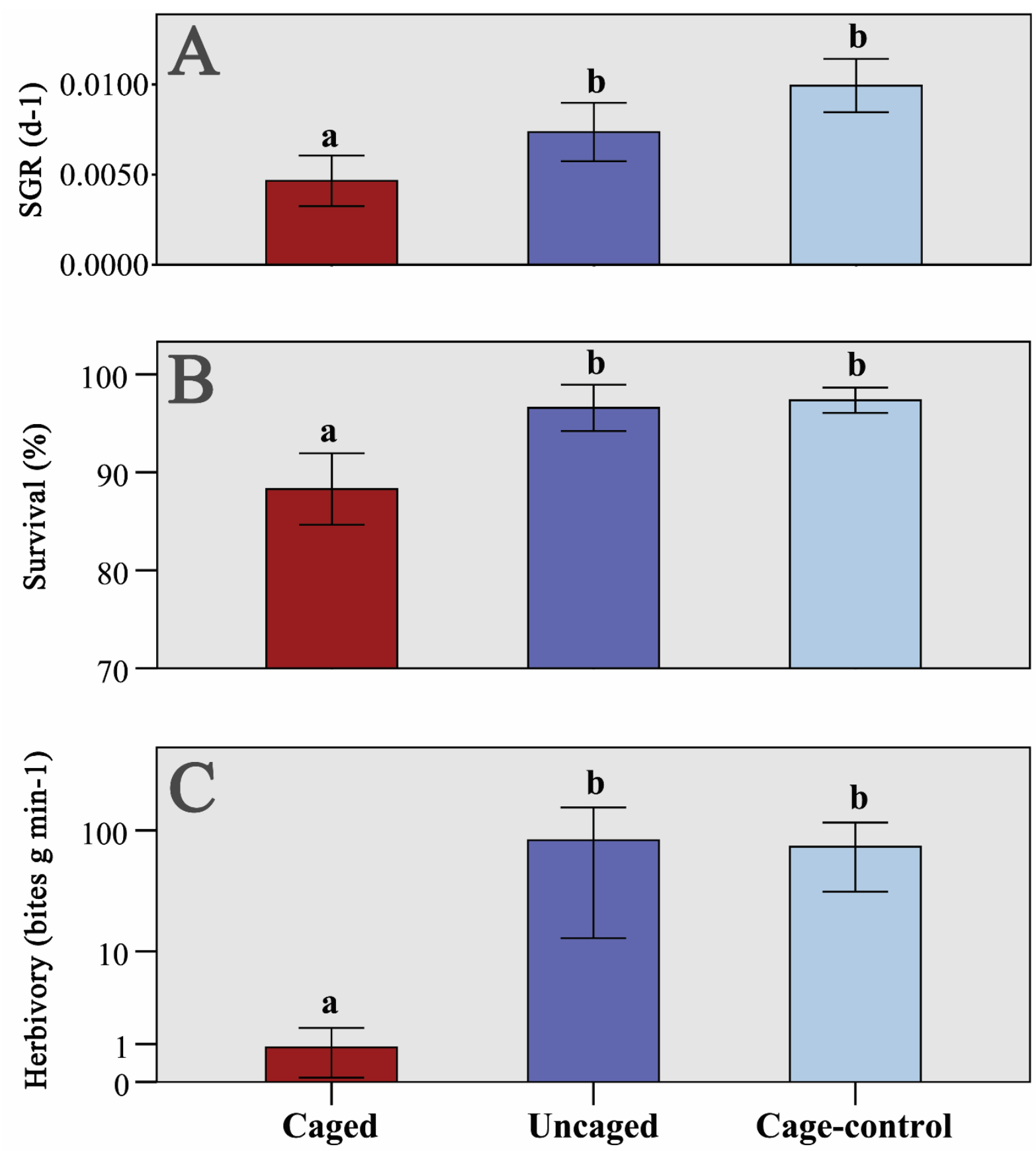

Fig. 3 Coral growth, survival and herbivory at caged (dark red), uncaged (blue) and cage-control (light blue) nursery structures. A Average specific growth rate (SGR) of Acropora verweyi during the 100-day experiment $(n=14-15)$. B Average survival (in percentage) of $A$. verweyi fragments at the end of the 100day study $(n=14-15)$. C Average rates of herbivory by fish (in mass-scaled bites per $\mathrm{min}$ ) as determined by remote underwater video observations in the caged $(n=19)$, uncaged $(n=31)$ and cage-control $(n=32)$ treatments. Bars represent means $\pm 2 \mathrm{SE}$. Differing lower case letters note a significant difference $(p<0.05)$ 


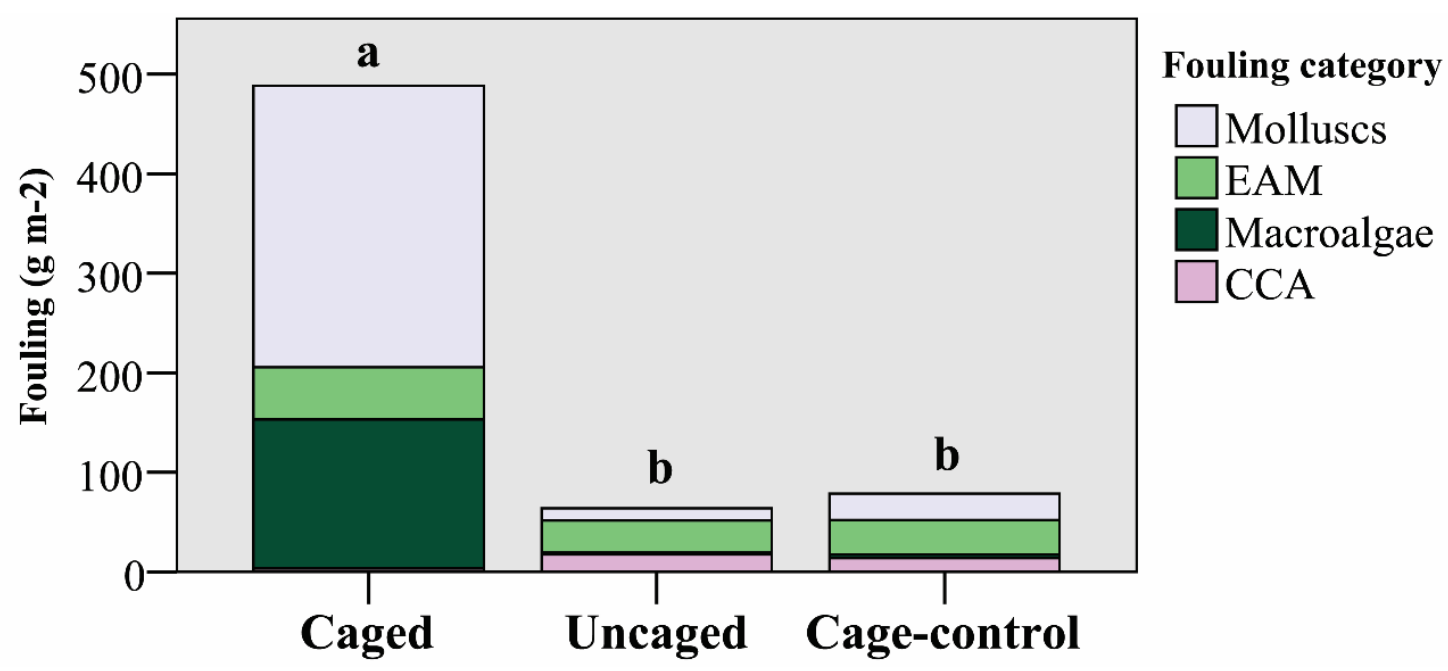

674 Fig. 4 Mean fouling density $\left(\mathrm{g} \mathrm{m}^{-2}\right.$ ) of molluscs (grey), epilithic algal matrix (EAM; green), macroalgae (dark green) and crustose coralline algae (CCA; pink) in the caged, uncaged and cage-control treatments $(n=12-14)$ at the end of the 100-day experiment. Differing lower case letters note a significant difference $(p<0.05)$ between the sum of all fouling categories. Fouling density of molluscs differed significantly between the three treatments; EAM did not differ significantly between treatments; macroalgae density was significantly higher in the caged treatment compared to both the uncaged and cage-control; CCA density was significantly lower in the caged treatment compared to both the uncaged and cage-control treatment 

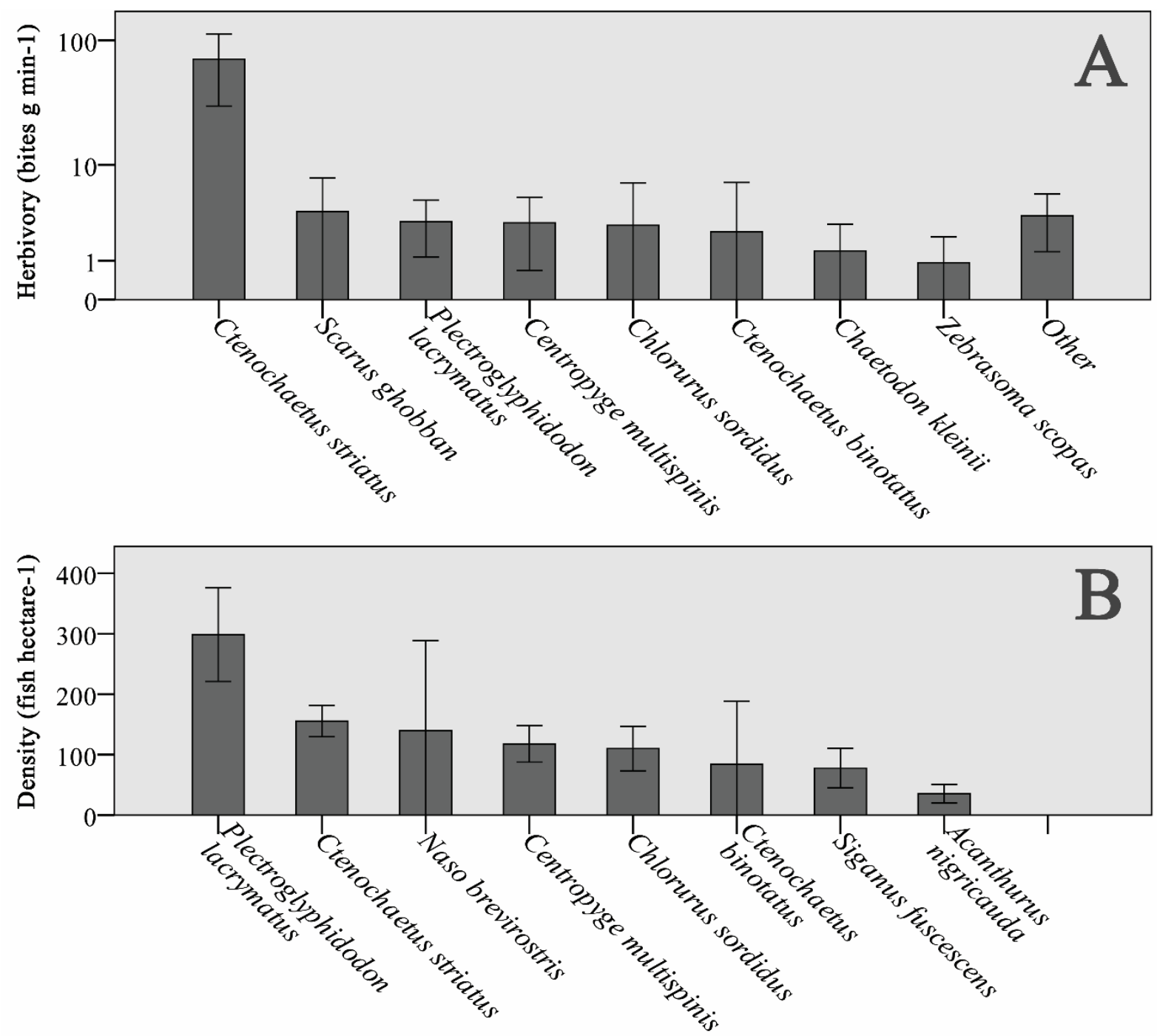

684 Fig. 5 Herbivory and fish density at the coral nursery structures. A Rates of herbivory (in mass-scaled bites per min) for the eight main grazing fish as determined by remote underwater video observations $(n=82)$. Bites of the less often occurring 24 species is summed under 'Other'. B Mean density (fish per hectare) of the eight most abundant roving herbivorous fish as determined by stationary underwater census $(n=51)$. Summed density of the remaining 132 fish has been omitted. Bars represent means \pm 2 SE 


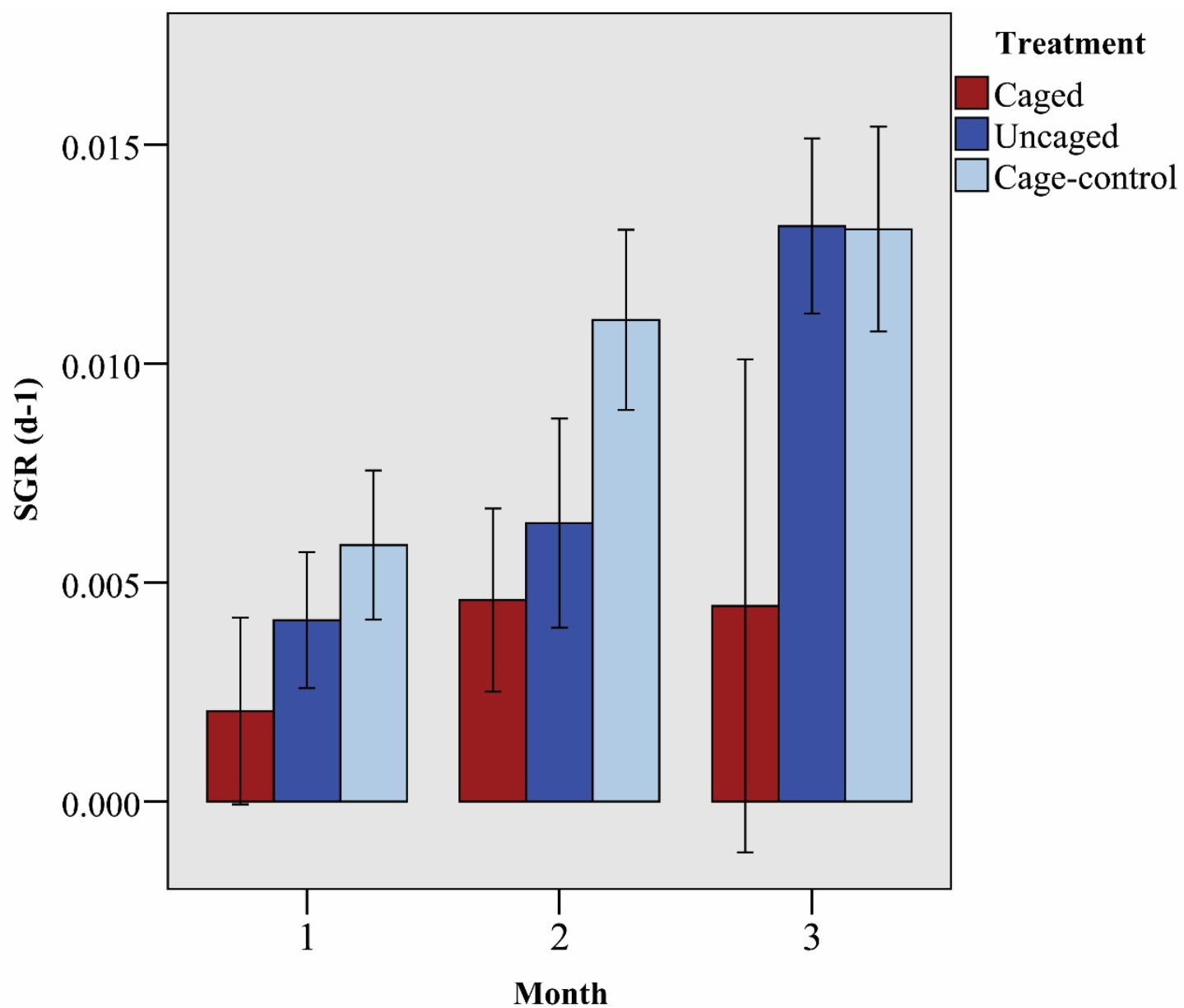

Fig. A1 Average specific growth rate (SGR) of Acropora verweyi for each month in the caged (dark red), uncaged (blue) and cage-control (light blue) treatments $(n=14-15)$. Bars represent means $\pm 2 \mathrm{SE}$. SGR differed significantly between the treatments (two-way mixed ANOVA, $\mathrm{p}<0.001)$ and increased significantly over time $(\mathrm{p}<0.001)$, but no significant interaction was found. 